\title{
Sensing Angular Kinematics by Embedding an Open-source Electronics De- sign Project into a Required Biomechanics Course
}

\section{Dr. Eric G Meyer, Lawrence Technological University}

Dr. Meyer directs the Experimental Biomechanics Laboratory (EBL) at LTU with the goal of advancing experimental biomechanics understanding. Dr. Meyer teaches Introduction to Biomechanics, Tissue Mechanics, Engineering Applications in Orthopedics, and Foundations of Medical Imaging. He has been an active member of the engineering faculty committee that has redesigned the Foundations of Engineering Design Projects course that is required for all freshmen in the College of Engineering at LTU. This committee is currently designing a new sophomore-level Engineering Entrepreneurship Studio that will also be required for all students as a continuation of the "Foundations Studio." He has published 33 peer-reviewed journal and conference proceeding articles. At LTU, Meyer offers a number of outreach programs for high school students and advises many projects for undergraduate students.

\section{Dr. Brent L Ulrey, Western New England University}

Brent Ulrey has worked as an engineer in the medical device and heavy industries. He holds a $\mathrm{PhD}$ in Biological Systems Engineering and MS degrees in Mechanical Engineering and Biomedical Engineering from the University of California, Davis. He received a BS in Mechanical Engineering from Alfred University in New York. His research interests include orthopaedic, occupational, and musculoskeletal biomechanics, as well as ergonomics. Dr. Ulrey is currently teaching mechanics and biomedical engineering courses at Western New England University. 


\title{
Sensing Angular Kinematics by Embedding an Open-Hardware Design Project into a Required Biomechanics Course
}

\begin{abstract}
Engineering courses have typically followed deductive pedagogy methods that are lacking in important student learning opportunities, such as; the reason why the concepts or mathematics are important, their real-world relevance, and how it will impact the students' future career in engineering. Project Based Learning (PBL) is an alternative method that is an inductive pedagogy, which begins with a real world problem or observation. In addition to the potential for improved student outcomes with inductive learning, the real world nature of PBL modules can lend itself for engineering design experiences that may also include broader Entrepreneurial Minded Learning (EML).

The goal of this project was to introduce a PBL module with a real world scenario into "Biomechanics" courses that cover the theory and methods for solving dynamics problems. In addition to learning the related angular kinematics concepts, this project required students to design a sensor-based system for the measurement and interpretation of 3D angular velocities during a specific human movement. The motivation for the project was a call for assistance help improve the university's baseball and softball teams' batting performance. Assignment questions guided the students through the engineering design process steps of; identifying customer needs, brainstorming, determining specifications, analyzing solutions. This was followed by informal presentations describing the initial concept to the "customer". Next, students were introduced to open-source electronics like Arduino and sensor platforms like SEEED Grove to use for the prototype development phase of the project. During an in class activity, they were provided a hardware kit and "recipe" instructions to set up and program the electronics as an angular velocity measurement sensor. Then they had to work with their partners outside of class to develop a calibration method for the sensors and to record the motions during a baseball swing. Finally, they developed a formal design report that refined their concept into a commercial product that could be marketed to the Baseball Coach and potential investors.

Student outcomes during pilot implementations at two universities were measured with direct (formal design report) and indirect (student survey) assessments. The instructors also maintained close observation of student groups in class and during office hours to reflect and improve the module's implementation.

There was a statistically significant increase in the rating of students' survey responses to entrepreneurship skills. Most students were able to collect and calibrate gyrometer sensor data and relate this information to the angular kinematics of a baseball swing. Although students had variable prior experiences with Arduino, they enjoyed the hands-on aspect of building a prototype. On the other hand, some students expressed confusion or did not appreciate the constraints imposed due to the staged nature of this project. The project was intended to reinforce the lecture topic of angular kinematics, but also introduced broader learning outcomes related to electronics and design.
\end{abstract}




\section{Introduction}

Traditional undergraduate courses in engineering have followed the deductive pedagogy of proposing a concept, explaining the principles and demonstrating mathematical models of the concept (Froyd et al., 2012). The student is expected to memorize the material or work many examples and their mastery is then evaluated during an exam. This teaching method lacks important student learning opportunities, such as; the reason why these concepts or mathematics are important, what is their realworld relevance and how this will impact the students' future career in engineering. Project Based Learning (PBL) is an alternative method that is an inductive pedagogy, which is more student-centered (Smith et al., 2005). These techniques begin with a real world problem or observation that is introduced to the students and can lead to deeper student learning when properly implemented Prince, 2004). In addition, the real world nature of PBL modules can lend itself for engineering design experiences that may also include broader Entrepreneurial Minded Learning (EML) (Kriewall and Mekemson, 2010). The aim is to develop students who are better at adapting to new trends, embracing creativity and leadership, understanding engineering impacts on society and business, as well as providing more opportunities to experience engineering design (Fairweather, 2008). Engineering design courses at the freshman or senior levels are the most common way that universities use to give students opportunities to work on real world engineering problems (Shartrand and Weilerstein, 2012). The EML pedagogy has been developed as techniques that emphasize students learning to create value, gather and assimilate information to discover opportunities or insights for further action (Melton, 2014).

Biomechanics is a sub discipline of Biomedical Engineering (BME) that is taught in some form in most undergraduate programs. The BME curriculum generally requires that students take courses covering "Statics", "Strength of Materials", and "Dynamics". They may also include a "Biomechanics Lab", as well as some more intermediate level courses such as "Tissue Mechanics" (Bowden et al., 2015). However, the exact semester sequence and the specific biological applications (ie. cardiovascular, orthopedic, kinesiology, tissue engineering, etc.) have little uniformity across different universities.

The goal of this project was to introduce a "Biomechanics" PBL module with a real world scenario into courses that cover the theory and methods for solving dynamics problems. The scenario was related to a recent, exciting trend in consumer electronics, which is the introduction of "Quantified Self" (QS) devices with sensors and data logging systems that allow individuals to track their health and activities. It is common to find students that own these devices, such as the Fitbit activity trackers, Withings smart scales, or Apple smart watch. Many QS devices are based on biomechanics concepts, such as kinematics (e.g. Microsoft Kinect and Nintendo Wii Remote) or kinetics (e.g. Wii Balance Board) to allow humancomputer interaction like immersive sports-based video games. By adopting QS as a running theme to motivate a variety of academic topics, students are given an opportunity to develop a mindset that fosters creativity and collaboration (Meyer and Nasir, 2015).

This paper describes the activity details, implementation, and assessment of student learning of a multi-week student project to design a sensor-based system for the measurement and interpretation of three dimensional angular velocities during a specific human movement. The PBL module was organized as a combination of in class, Active Collaborative Learning (ACL) and partner based design project 
homework. The module was implemented in different BME courses by two faculty at two different universities.

Activity Details - Group project “Angular Kinematics” Sensor Design

The activity was implemented over a span of 2-3 weeks. The following learning objectives were emphasized with the module:

Biomechanics Topics

- Demonstrate the ability for self-directed learning by organizing and delivering effective written and verbal communication on the biomechanical function of the human body.

- Identify research tools in biomechanics and examples of the relevant fields that this data could be used in.

- Determine the linear and angular kinematics of particles and rigid bodies for biomechanical applications.

- Demonstrate the use of motion capture tools for the measurement of dynamic human movement activities.

Engineering Design/Entrepreneurship Topics

- Define problems, opportunities, and solutions in terms of value creation.

- Create a preliminary model.

- Communicate engineering solutions in economic terms and with regard to societal benefits.

Scenario: The Lawrence Tech baseball and softball coaches have contacted you because of your expertise in biomechanics. The teams need to improve their batting performance but has not been able to understand what human dynamics aspect needs to be focused on or what training they should practice to improve. You and your partner will form a new company to develop a product that can address this opportunity. Specifically, the product should include technology that measures the kinematics of a bat during a swing. The final product should be user-friendly under real world conditions and provide analysis of the measured data to help baseball players improve their performance.

Instructions: Work with a partner of your choosing. Submit one Final Report and prepare one Elevator Pitch for your group with the format indicated (see appendix). The design worksheet and sketches do not need to be typed, but should be neat so that we can discuss your work. Explain your steps and show all of your work clearly. A good design with a poor explanation may appear like a bad design. Think creatively and thoroughly. Provide all necessary biomechanics background information and any references or examples that will help explain your design concept.

\section{Assessment Methods}

Direct assessment of the assignment questions, final report using a grading rubric (see appendix), and final pitch presentations was completed to determine if the students addressed the engineering design steps and reached the expected level of attainment of the biomechanics technical content. Following the normal course "Key Performance Indicators" assessment criteria in the BME Department at Lawrence 
Technological University (LTU), the classification "Excellent" is applied when students demonstrate the ability to apply knowledge with virtually no conceptual or procedural errors as demonstrated by a nominal grade between $100 \%-90 \%$, while "Acceptable" is applied when there are no significant conceptual errors and only minor procedural errors and a nominal grade between $89 \%-70 \%$. Lower classifications are "Minimal" and "Unsatisfactory". Indirect assessment of the students by means of confidential, pre and/or post module surveys were used to gauge the effectiveness of the module at changing students' perceptions and improving their entrepreneurial mindset (Table 1). The questionnaire was approved by the Western New England University (WNE) Institutional Review Board, and the students were informed of their rights to not participate. Paired t-tests were performed on each question's pre versus post scores with statistically significant differences indicated by $\mathrm{p}<0.05$. After the module, the students were also asked to provide comments.

Table 1. Questions on the pre-module and post-module surveys. The students rated each question 0,1 , 2,3 , or 4 , with 0 representing a low level and 4 representing a high level of knowledge/ability.

1. Please rate your current level of knowledge/ability regarding opportunity recognition and solutions in terms of value creation.

2. Please rate your current level of knowledge/ability regarding creating a preliminary model.

3. Please rate your current level of knowledge/ability regarding communicating solutions in terms of societal benefits.

4. Please rate your current level of knowledge/ability regarding examining technical feasibility, economic drivers, and societal and individual needs.

5. Please rate your currently level of knowledge regarding entrepreneurship and the entrepreneurial mindset.

\section{Implementation}

The module was implemented following a similar methodology and time line in two classes at two different universities. In the first implementation, it was during a lecture-based "Introduction to Biomechanics" course at LTU that was required for BME juniors who had already completed a semesterlong "Statics" course and were concurrently taking "Biomechanics Lab". There were 13 students in this course. The second implementation was in a "BME Senior Lab" course at WNE. This required course was taken by twenty senior biomedical engineering students who were also enrolled in a second semesterlong "Biomechanics" course that focused on dynamics topics. The curricular differences between the two university programs created some expected differences in student's experiences/capabilities. The junior level students had laboratory experience with measuring human motions using a three dimensional motion capture system, while the senior level students' laboratory experiences did not include this biomechanics experience. On the other hand, the senior students were also working on their "Senior Design Projects" and may have had more experiences with engineering design and entrepreneurship.

During the first class period (Table 2), the students formed groups of 2-3 and each group member chose one of the two "expert groups" to investigate either baseball/softball swing performance or kinematics measurement techniques. Limited suggestions for online resources were given to each expert group to get started, but the emphasis was that they work together to find the necessary information. As the in-class period was wrapping up, the partner groups reformed and a brief class discussion recapped some important information that was expected to be found by each of the expert groups (Figure 1). Finally, 
a guided design process homework assignment was given. Groups had to brainstorm a list of at least 20 of biomechanical methods/ performance characteristics that could be included in their product concept and to answer the following questions:

- Identify customer needs and describe the value proposition of a product/service concept for potential customers.

- Define selection criteria and refine your brainstorm list to three concepts that address at least one of the customer needs.

- Elaborate on how each concept would function with sketches/diagrams and components. Develop the marketing concepts with storyboards/simulations about what the product looks like and how it would be used.

- Develop a business model around this product/service. What are the business costs and what is the price for consumers, or how would you generate revenue?

- Do you think that your customer target would be interested in purchasing and using this product/service? How would you validate this claim?

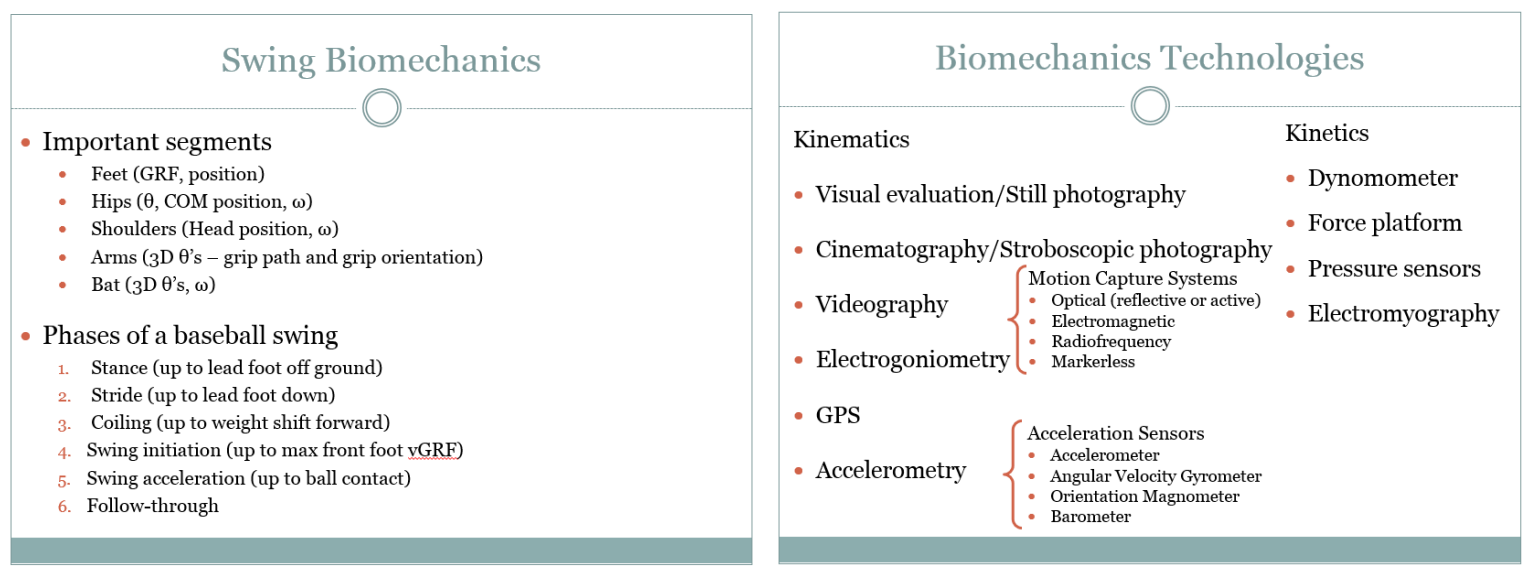

Figure 1: Biomechanics' concepts slides for in class discussion.

During the second week, each group informally presented their initial ideas to the class and got recommendations. Then, the prototype hardware (Figure 2) was supplied to each group and the setup was introduced with an in class demonstration (see Appendix). All the groups were able to successfully upload the "Blink" example program. Then, they connected a three axis accelerometer, uploaded the control program and were able to record real-time data using the Arduino IDE serial monitor. By rotating the accelerometer relative to gravity, they were able to determine correspondence between the three axes and the three channels of data. They could also check the data acquisition rate and the calibration relative to the known acceleration of Earth's gravitational field. The remainder of work building and calibrating the prototype with a three axis angular velocity gyrometer sensor was assigned as homework. Other design specifications and requirements included:

- Be sure to include a way to calibrate your sensor, so that the analyzed data can be compared with other methods.

- Develop "instructions for use" to acquire reproducible and understandable swing kinematics data from athletes.

- The built prototype may not be user friendly and packaged in a "finished" consumer form, but your final product design should include descriptions of these features. 
Other considerations included:

- What coaching/training considerations are important to improve batting performance?

- What are the key features of your product?

- To whom and how would you market your final product? Think beyond 'Lawrence Tech baseball/softball'.

- What is the final cost, manufacturing and distribution methods envisioned for your product?
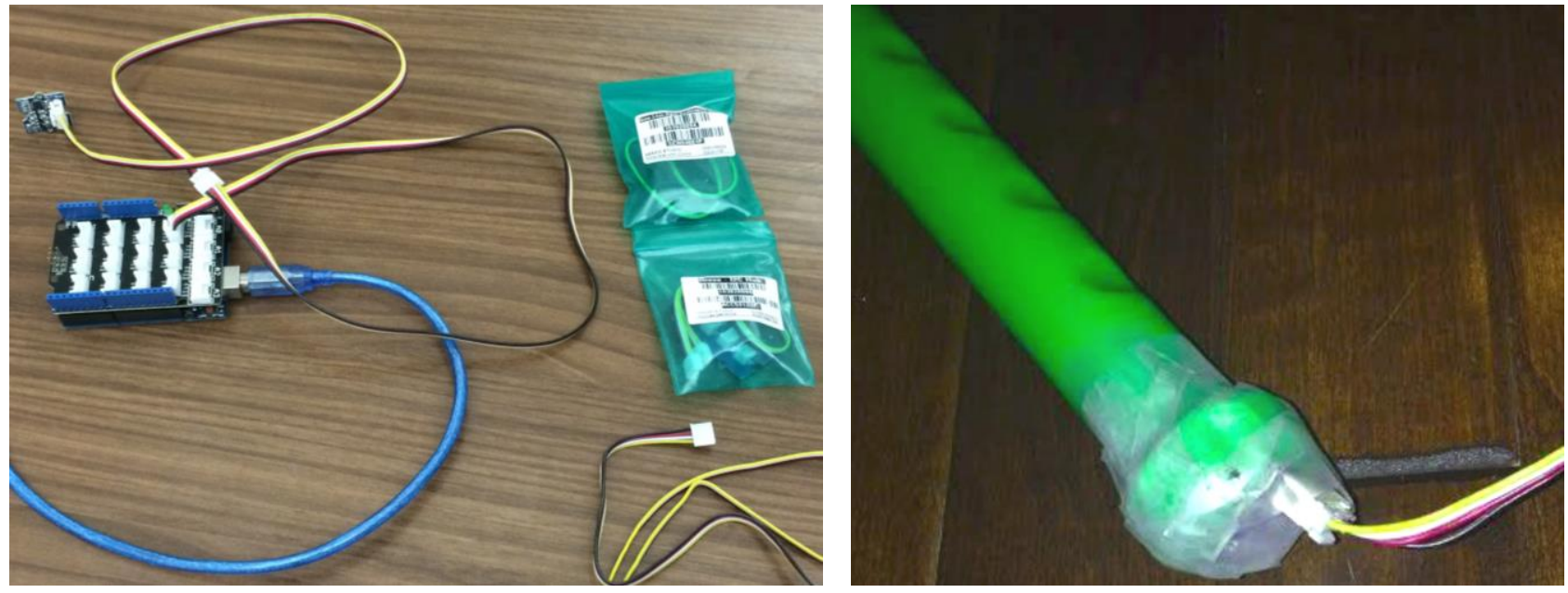

Figure 2: Arduino Uno and SEEED Grove sensor kits supplied for device prototyping.

During the third week, each group gave their final 60 second "elevator pitch" presentations of the design concepts and turned in their final reports. Class discussion followed the pitch to recap the project's highlights and challenges. This discussion included other similar devices that are available on the market, such as the Zepp swing sensor for baseball/softball, tennis, or golf. An expected difficulty in the calibration of the data was relating the three axes of angular velocity with the biomechanical angular orientations. Therefore, additional channels of data like orientation magnometer sensors are necessary for accurate three dimensional motion measurement in devices like the Zepp.

Table 2: Course schedule of "Angular Kinematics" Sensor Design module activities.

\begin{tabular}{|c|c|c|}
\hline Week & In class & Out of class \\
\hline 6 & $\begin{array}{l}\text { - Angular kinematics lecture } \\
\text { - Expert group information } \\
\text { gathering } \\
\text { - Design groups start brainstorming }\end{array}$ & $\begin{array}{l}\text { - Follow guided design process } \\
\text { assignment }\end{array}$ \\
\hline 7 & $\begin{array}{l}\text { - Recap engineering design and } \\
\text { entrepreneurship concepts } \\
\text { - Demonstration of prototype } \\
\text { hardware setup } \\
\text { - Determine calibration/acquisition } \\
\text { methods }\end{array}$ & $\begin{array}{l}\text { - Complete prototype and prepare final } \\
\text { design }\end{array}$ \\
\hline 8 & $\begin{array}{l}\text { - Check in with groups for problems } \\
\text { - Deliver "elevator pitch" } \\
\text { presentations }\end{array}$ & - Turn in final report \\
\hline
\end{tabular}




\section{Assessment Results}

In general, most students seemed to enjoy the assignment. They understood the importance of design in engineering and were able to communicate their product concept in terms of technical capability, customer value and economic viability. They were able to collect and calibrate sensor data and relate this information to the angular kinematics of a baseball swing. Although many students had no prior experience with Arduino, they enjoyed the hands-on aspects of building a prototype. On the other hand, some students expressed confusion at the start of the project or did not appreciate the staged nature of the module's organization.

Direct assessment results showed that all six of the design groups at LTU produced acceptable or excellent results for the final design report. Specific grading criteria for technical content categories of; design process, prototype results, and final product descriptions, were also all assessed as acceptable or excellent. Five out of six groups produced reports that included high quality images to describe the concept and prototype testing methods. On the other hand, all of the groups could have improved their calibration description and graphical presentation of the testing data.

Fifteen of the students at WNE completed both the pre and post module surveys (Table 3). There was a statistically significant increase in the rating of questions 1,2 , and 4, related to opportunity recognition, creating a preliminary model, and examining technical feasibility, respectively.

Table 3. Results of the pre-module and post-module surveys at WNE.

\begin{tabular}{|c|c|c|c|c|c|}
\hline Question & \multicolumn{2}{|c|}{ Pre } & \multicolumn{2}{c|}{ Post } & P-Value \\
\hline & Mean & Std. Dev. & Mean & Std. Dev. & \\
\hline 1 & 2.40 & 0.74 & 2.93 & 0.80 & 0.0133 \\
\hline 2 & 2.33 & 0.98 & 2.93 & 0.88 & 0.0070 \\
\hline 3 & 2.73 & 0.80 & 3.00 & 0.76 & 0.1085 \\
\hline 4 & 2.53 & 0.64 & 2.93 & 0.70 & 0.0140 \\
\hline 5 & 2.27 & 0.80 & 2.47 & 0.83 & 0.1671 \\
\hline
\end{tabular}

The feedback included positive comments such as, "I have learned how to develop a preliminary model with limited resources," and, "I learned how to develop a solution to a real problem quickly." There were some questions during the brainstorming session about which parts would be available the following week; some students wanted to know what parts would be provided. The students were reminded not to constrain their designs during this stage. Other comments addressed the constraints of the assignment such as, "Sensor selection seemed too focused; limited options for designs," and, "Possibly more time or more parts to use."

\section{Discussion and Conclusions}

PBL is an effective vehicle for including inductive learning pedagogies into technical engineering courses as well as giving students experiences with engineering design and entrepreneurship. On the other hand, technical engineering courses are required to cover a large number of topics with sufficient examples and therefor require efficient knowledge transfer. The project was implemented to coincide with the course 
schedule to reinforce the lecture topic on angular kinematics. It required about 2 hours of in class time, out of a 45 hour course, but introduced new broader learning outcomes related to electronics and design that students may not get outside of dedicated classes. By limiting the duration of the PBL and amount of in class time spent, none of the regularly cover topics had to be eliminated from the course. However, the expectation level for the design project reports reflected the short-term nature of this project and improvements or customization to hardware design and calibration methods would require additional course time. The hardware kits and instructions took preparation time and cost approximately $\$ 50$ /group, but can be reused in future course offerings. The design project also required significant (but unmeasured) group homework time to complete.

This course module was part of a larger project to implement EML into a variety of engineering courses so that students will get repeated experiences throughout their curriculum. These skills are essential for students during senior projects and in their professional engineering careers. Therefore, it may be better to offer more choices of parts or allow the students to order their own parts. Having each group order their own parts would take more time during the semester; however, having more types of parts and sensors would allow for more diverse designs.

Future work for this project includes implementing module revisions in subsequent course offerings as well as similarly structured PBL modules with different scenarios and hardware in other technical engineering courses in the BME curriculum. Additional assessment data will be collected and analyzed to more formally determine the effect of this PBL on student's technical and entrepreneurship skills. The ultimate goal is to use these repeated engineering design experiences to reinforce skills into habits and to build students' confidence.

\section{References}

Bowden A, Ochia R, Eggett DL. Survey of U.S. Biomechanics Instruction. Proc ASEE Annual Conference, 2015, Seattle, WA.

Fairweather J. Linking Evidence and Promising Practices in Science, Technology, Engineering, and Mathematics (STEM) Undergraduate Education, National Research Council's Workshop Linking Evidence to Promising Practices in STEM Undergraduate Education, 2008, Washington, DC.

Froyd JE, Wankat PC, and Smith KA, Five Major Shifts in 100 Years of Engineering Education, 2012, Proc. of the IEEE, 100, 1334-57.

Gerhart AL, Carpenter DD. Campus-wide Course Modification Program to Implement Active \& Collaborative Learning and Problem-based Learning to Address the Entrepreneurial Mindset. Proc. ASEE Annual Conference, 2013, Atlanta, GA.

Kriewall T, Mekemson K. Instilling the entrepreneurial mindset into engineering undergraduates, J Engineering Entrepreneurship, 2010, 1, 5-19.

Melton D. Bridging the Knowledge Gap: KEEN Program Director Doug Melton on entrepreneurially minded learning from a student and faculty perspective. KEEN'zine. 2014:2;6-7. 
Meyer EG, Nasir M. Fostering the entrepreneurial mindset through the development of multidisciplinary learning modules based on the "Quantified Self" social movement. Proc ASEE Annual Conference, 2015, Seattle, WA.

Prince M. Does active learning work? A review of the research. Journal of Engineering Education. 2004:93(3);223-231.

Smith KA, Sheppard, SD, Johnson DW, and Johnson RT, Pedagogies of Engagement: Classroom-Based Practices. Journal of Engineering Education. 2005:94(1);87-101. 


\section{Appendix}

\section{Lawrence Technological University BME 3303 "Biomechanics"}

Group Project “Angular Kinematics" Sensor Design

\section{Instructions:}

Work with a partner of your choosing. Submit one Final Report and prepare one Elevator Pitch for your group with the format indicated (see appendix). The design worksheet and sketches do not need to be typed, but should be neat so that we can discuss your work. Explain your steps and show all of your work clearly. A good design with a poor explanation may appear like a bad design. Think creatively and thoroughly. Provide all necessary biomechanics background information and any references or examples that will help explain your design concept.

\section{Final Report Format:}

Abstract - This section is one paragraph or two short paragraphs that briefly describes the main components of your design. It should be a stand-alone section.

Introduction - Background theory and existing solutions for the opportunity to be addressed. Describe the problem to be solved, objectives/goals, and assumptions.

Design Process - Describe initial brainstorm options, selection criteria, refined options with detailed sketches/components, and selection of a built prototype. Always label (caption) any figures. As common practice, any figure in the report must be discussed somewhere in the text.

Prototype Results - Include photographs of the device and testing. Show data to support or reject this design's function.

Description of Final Product - Include a comprehensive schematic(s) of your final design. Include details of all components. Be logical in your sequence of this section.

Conclusion - Summarize the features of your design, the estimated cost to produce it, and whether the cost is worth the benefit gained.

References - Use a standard format for references.

Appendix - Include hand calculations, lengthy computer print-outs, or anything else that supports your design but is not necessary in the main report. Everything in the Appendix should be noted in the report. For example, "Appendix A shows the detailed calculations of the previous result." Otherwise, the material does not belong in the Appendix and hence the report.

\section{Elevator Pitch Format:}

Formalize the information presented in your final report into a refined, approximately 60 second "elevator pitch" that you could give to the baseball coaches, softball coaches, and potential investors. Develop an interesting story that explains your product design concept and business model. Provide justification for your targeted customers and value proposition. Clearly illustrate how the device will be incorporated into this product and service concept. No presentation slides or images can be used. 


\section{Lawrence Technological University \\ BME 3303 "Biomechanics"}

"Angular Kinematics" Sensor Design Prototype Setup

\section{Introduction to Arduino}

Read the "What is Arduino" documentation to become familiar with this type of Open Source Hardware.

\section{Materials}

- Arduino Uno

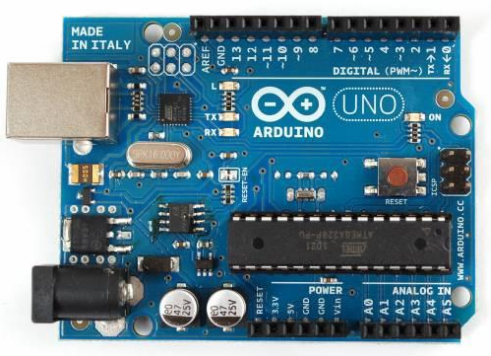

- Grove 3-Axis Accelerometer ( $\pm 16 \mathrm{~g})$

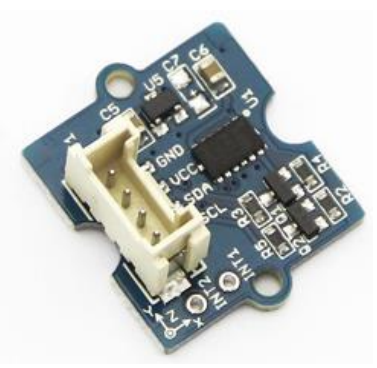

- Grove Cables

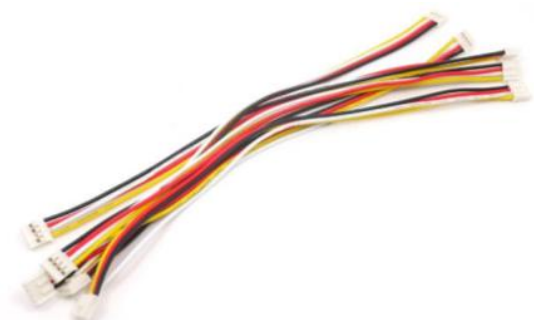

- Grove Base shield v2

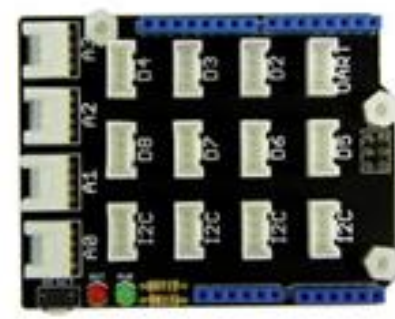

- Grove 3-Axis Digital Gyro

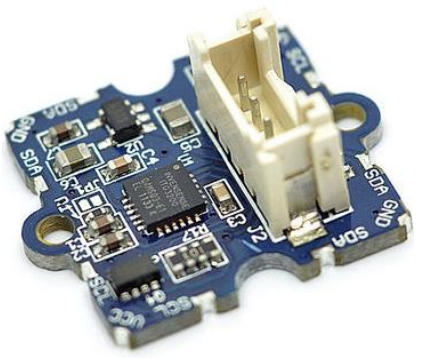

- $12 \mathrm{C}$ Hubs and pin connectors

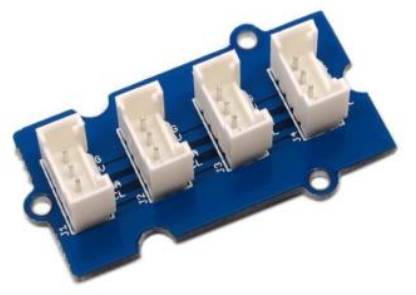

\section{Arduino Software (IDE) \& Setup}

1. Unpack you Arduino Uno board and USB Cable.

2. Download the latest version of the Arduino Software from https://www.arduino.cc/en/Main/Software *Note: Arduino IDE version 1.6.5 was used when this guide was written

3. Install the Arduino software and drivers to your computer by following the instructions based on your version of Windows in the "Getting Started with Arduino" guide.

4. Connect the Arduino board to your computer using the USB cable. The green power LED (labelled PWR) should go on. 
5. Launch Arduino IDE by double-clicking the Arduino application (arduino.exe) you have previously downloaded.

6. To test if your Arduino is working properly you should run the Blink test program. To do this you will first need to select your board and COM port. Go to Tools >> Board and choose Arduino Uno. Next go to Tools $\gg$ Serial Port and choose the COM port labeled with Arduino Uno.
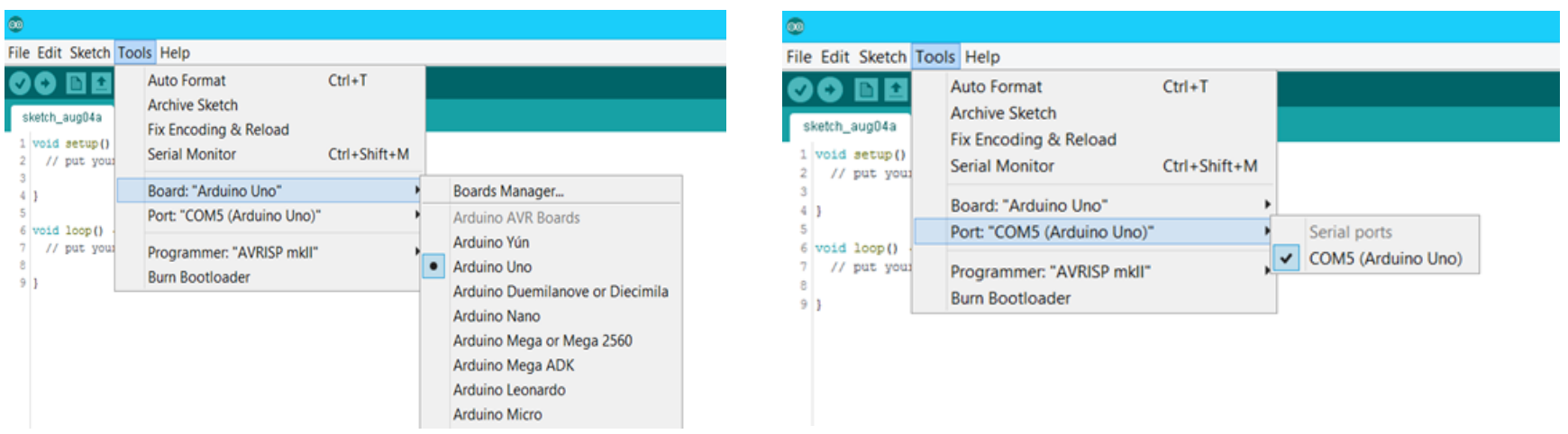

7. Open the Blink test program by going to File $\gg$ > Examples $\gg$ > 1. Basics $\gg>$ Blink.

8. Now, simply click the "Upload" button in the environment. Wait a few seconds - you should see the RX and TX LEDs on the board flashing. If the upload is successful, the message "Done uploading." will appear in the status bar.

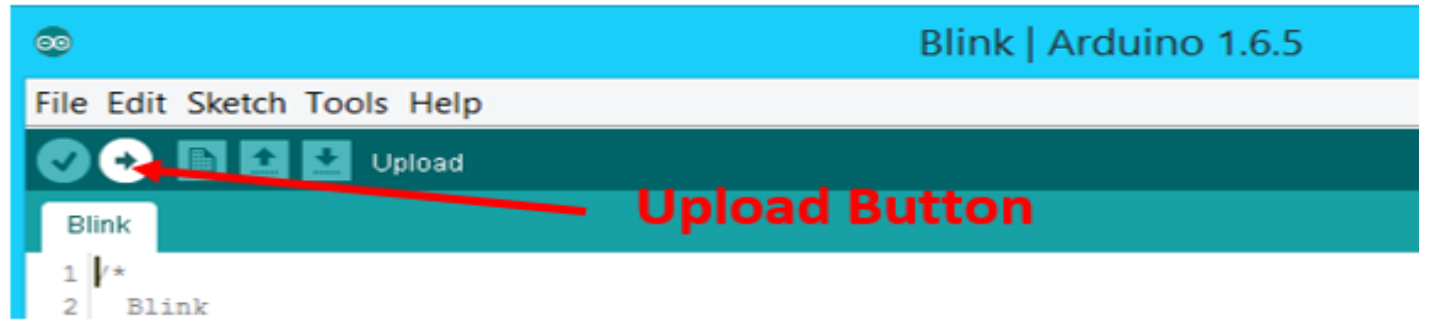

A few seconds after the upload finishes, you should see the pin 13 (L) LED on the board start to blink (in orange). If it does, congratulations! You've gotten Arduino up-and-running.

\section{Grove Software and Setup}

1. Download Grove_3_Axis_Digital_Gyro (Library zip folder) from Blackboard.

*Note: The zip folder can also be downloaded at the following link: http://www.seeedstudio.com/wiki/Grove - 3-Axis Digital Gyro

2. In the Arduino application go to Sketch $>$ Include Library $>>$ Add .ZIP Library and find your downloaded Grove_3_Axis_Digital_Gyro Library folder and open it. 


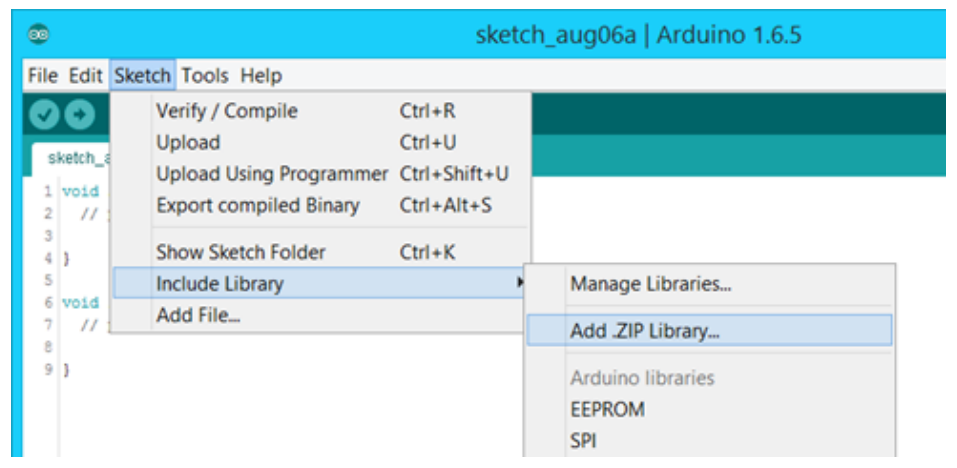

\section{Setting up the Grove Sensor Prototype}

3. Place the Base Shield onto the Arduino Uno as shown below. Make sure you do not bend the pins when doing this.

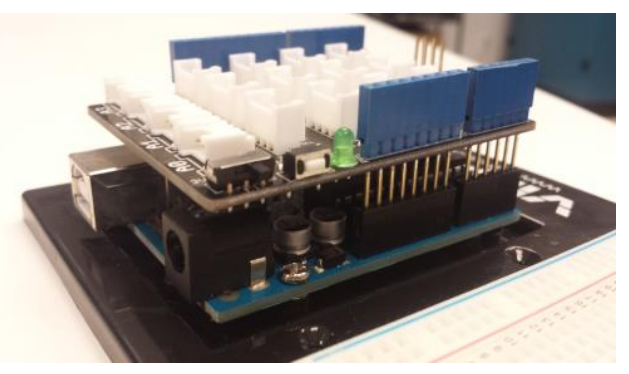

4. Grab and connect two Grove Cables to the $12 \mathrm{C}$ hub. Then attach one cable to the Grove 3-axis Accelerometer and attach the other to any of the $12 \mathrm{C}$ ports on the Grove shield.

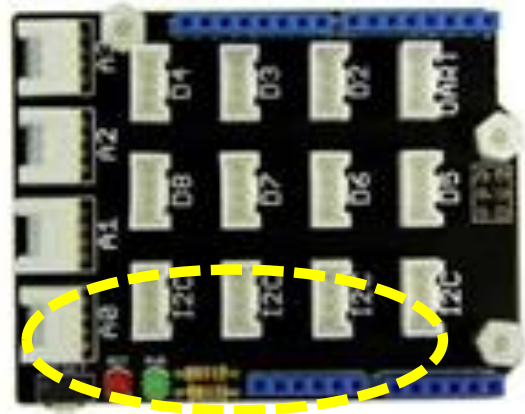

\section{Uploading Code}

5. Go to File >> Open and open the ITG3200_gyro Folder with similarly named Arduino file.

6. With the Arduino Uno attached to the computer via the USB, click on the green arrow under Edit to upload the code to the Arduino Uno.

\section{Recording Data}

1. Open up the serial monitor (shown as a magnifying glass in the upper right corner of the Arduino software. 


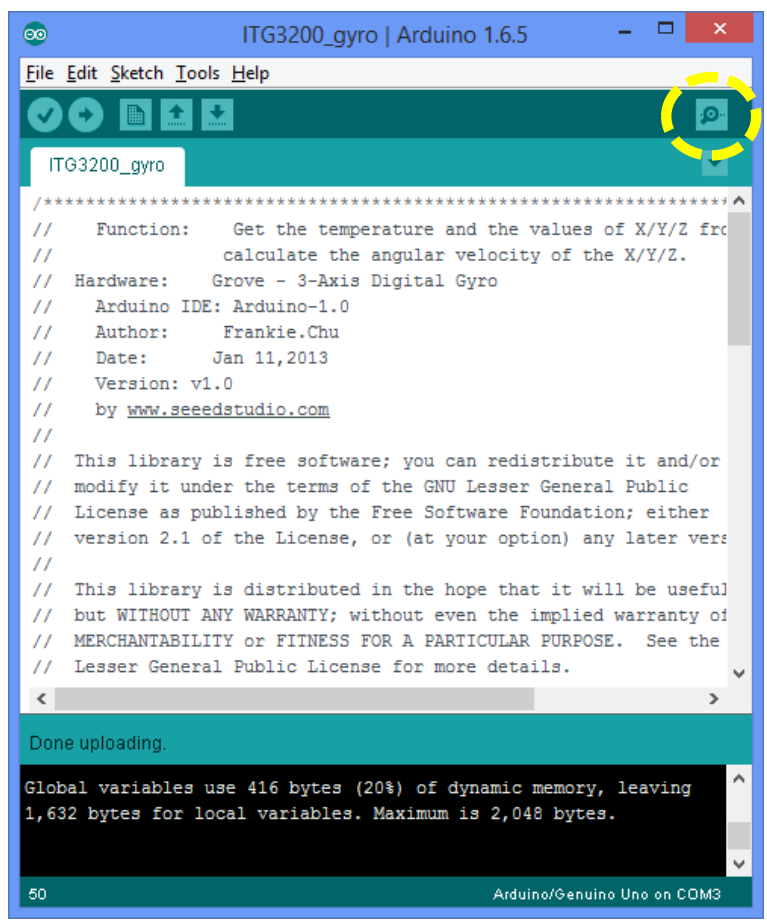

2. At the bottom left corner of the COM port serial monitor window that appears, you can uncheck "Autoscroll" to view different timepoints of data.

3. Copy the data of interest by selecting those lines and pressing $\mathrm{Ctrl}+\mathrm{C}$ on the keyboard.

4. Open a new Excel sheet and paste the columns of data into a spreadsheet. Insert an empty column to the left of the data to add the time column manually. You will have to calculate the timestep interval or determine it from the Arduino program.

5. Select the four columns of data and click the Insert:Chart "Scatter with Straight Lines"
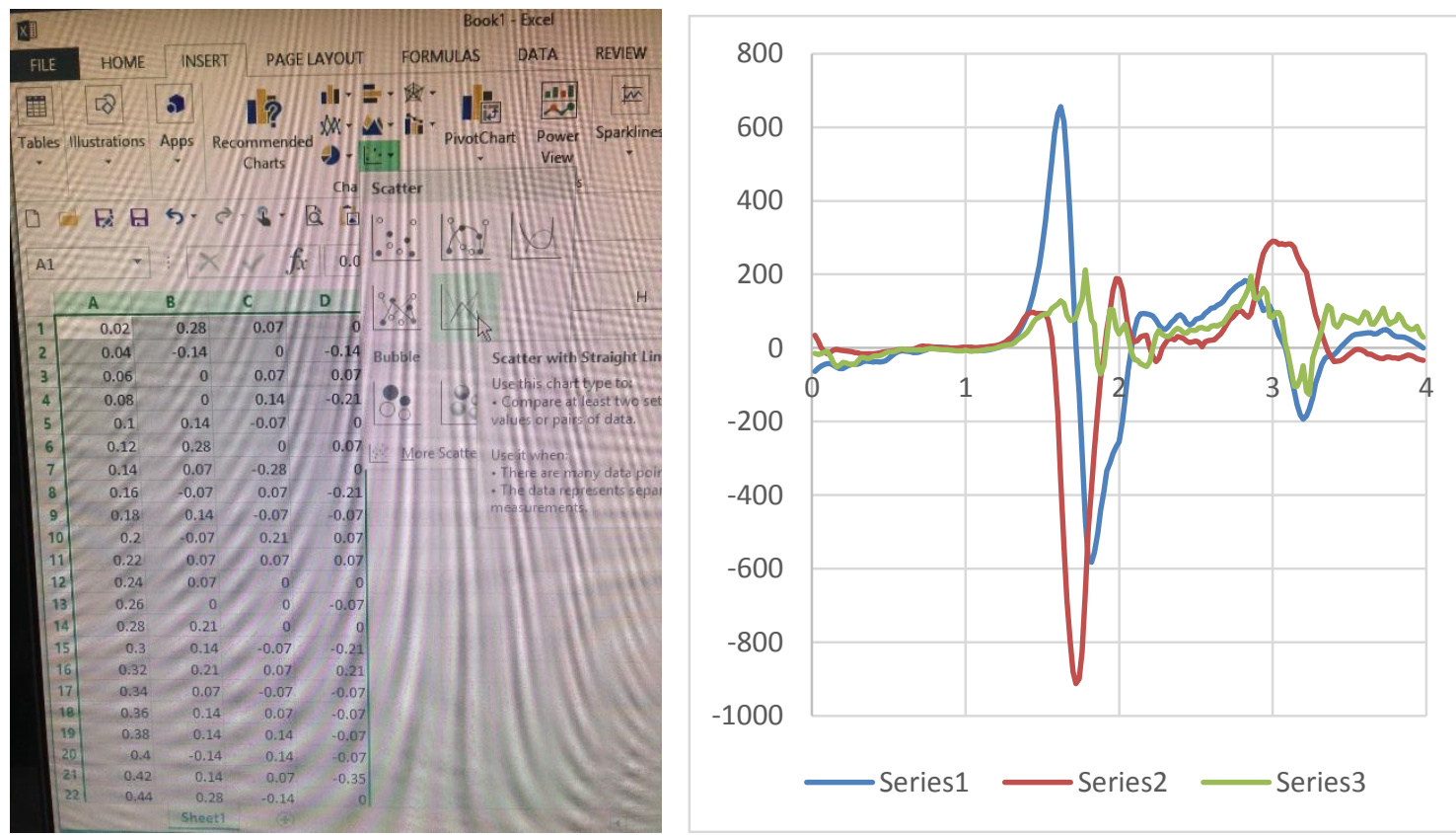
6. Determine which of the three axes corresponds to the particular directions that are indicated on your sensor. Determine the units of angular velocity that are being reported. See the "Grove -3-Axis Digital Gyro" and "ITG-3200" documentation for more details.

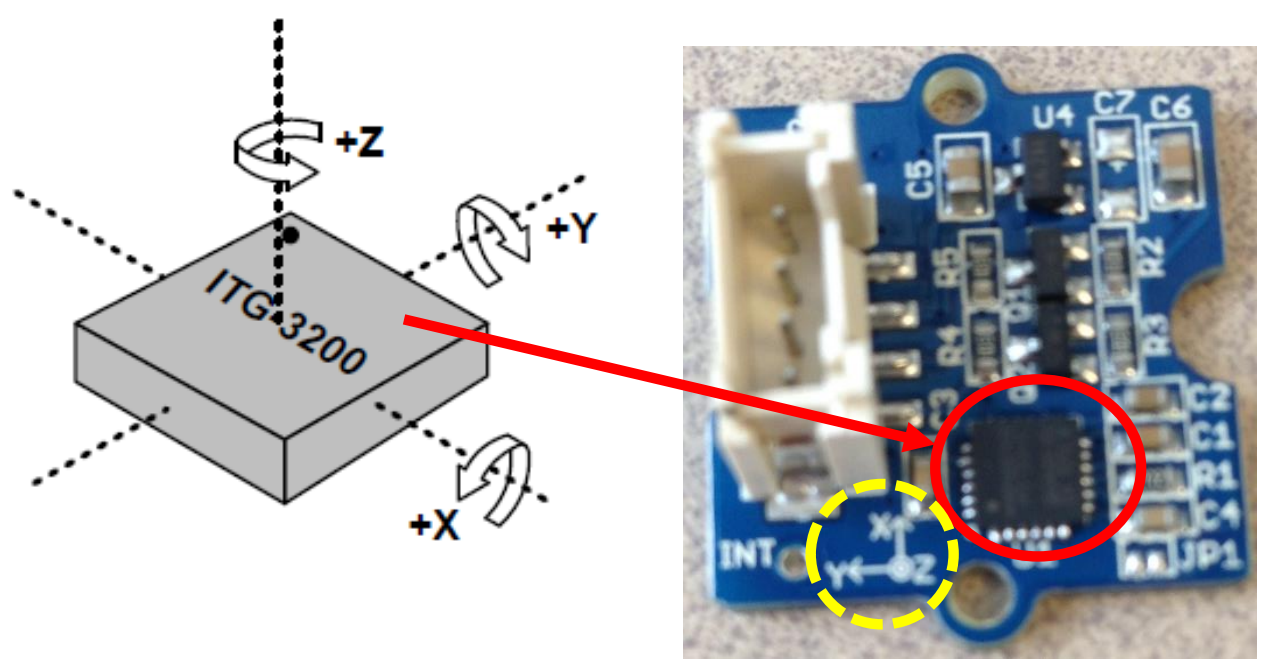

Alternatively, you can find other program and setup files for different Grove sensors, such as Grove_Accelerometer (Arduino program) and L3DigitalAccelerometer_ADX45 (setup file). http://www.seeedstudio.com/wiki/File:DigitalAccelerometer ADXL345.zip

There are many sensors available if you want to include other measurements in your final design. 


\section{Lawrence Technological University BME 3303 Introduction to Biomechanics}

Design Project Grading Rubric Names

\begin{tabular}{|c|c|c|c|c|c|}
\hline \multicolumn{6}{|c|}{ Participation } \\
\hline Criteria & $\begin{array}{l}\text { Does Not Meet } \\
\text { Expectations }\end{array}$ & Meets Expectations & Exceed Expectations & Weight & Score \\
\hline $\begin{array}{l}\text { Initial Ideas } \\
\text { Presentation }\end{array}$ & Incomplete, little effort. & Good effort, mostly complete. & Highly motivated, detailed. & 5 & \\
\hline Prototype Setup & Absent, not participating. & Present, participating. & Fully engaged. & 5 & \\
\hline $\begin{array}{c}\text { Final Pitch } \\
\text { Presentation }\end{array}$ & Incomplete, little effort. & Good effort, mostly complete. & Highly motivated, detailed. & 5 & \\
\hline $\begin{array}{l}\text { Management/ } \\
\text { Execution }\end{array}$ & $\begin{array}{l}\text { Very little effort put into the } \\
\text { project. }\end{array}$ & Good work ethic, team-effort. & $\begin{array}{l}\text { Highly motivated. Good } \\
\text { distribution of work. }\end{array}$ & 10 & \\
\hline \multicolumn{6}{|c|}{ Technical Content } \\
\hline Criteria & $\begin{array}{l}\text { Does Not Meet } \\
\text { Expectations }\end{array}$ & Meets Expectations & Exceed Expectations & Weight & Score \\
\hline Abstract & $\begin{array}{l}\text { Fails to clearly summarize the } \\
\text { project objective, results and } \\
\text { conclusions. }\end{array}$ & $\begin{array}{l}\text { Adequate and understandable } \\
\text { summary of the project objective, } \\
\text { results and conclusions. }\end{array}$ & $\begin{array}{l}\text { Thorough and clear summary of } \\
\text { the project objective, results and } \\
\text { conclusions. }\end{array}$ & 5 & \\
\hline Introduction & $\begin{array}{l}\text { Little material has been } \\
\text { assembled and has not been } \\
\text { understood. The theory } \\
\text { explanations are vague, wrong, or } \\
\text { entirely absent }\end{array}$ & $\begin{array}{l}\text { Most relevant material has been } \\
\text { collected and presented in a } \\
\text { logical manner. Most statements } \\
\text { referenced and theory explained. }\end{array}$ & $\begin{array}{l}\text { All relevant material assembled } \\
\text { and digested and is presented in } \\
\text { a logical manner. All statements } \\
\text { are referenced and theory } \\
\text { explained. }\end{array}$ & 5 & \\
\hline Design Process & $\begin{array}{l}\text { The procedure is poorly } \\
\text { documented and unjustified. } \\
\text { Descriptions are incomplete. }\end{array}$ & $\begin{array}{l}\text { The procedure is documented. } \\
\text { Designs follow the design } \\
\text { process, and other methods/ } \\
\text { designs are evaluated. }\end{array}$ & $\begin{array}{l}\text { Procedure is comprehensively } \\
\text { justified. Follow the design } \\
\text { process and methods/designs are } \\
\text { thoroughly evaluated. }\end{array}$ & 10 & \\
\hline $\begin{array}{l}\text { Prototype } \\
\text { Results }\end{array}$ & $\begin{array}{c}\text { The results are confusing and } \\
\text { there is little analysis. There are } \\
\text { significant gaps in the expected } \\
\text { project outcomes. }\end{array}$ & $\begin{array}{l}\text { The results are displayed with } \\
\text { some consideration of the project } \\
\text { objectives. There is some analysis } \\
\text { and discussion. }\end{array}$ & $\begin{array}{l}\text { The results are displayed in an } \\
\text { easily understood manner and } \\
\text { referenced to the objectives. } \\
\text { There is a detailed analysis. }\end{array}$ & 10 & \\
\hline $\begin{array}{l}\text { Final Product } \\
\text { Description }\end{array}$ & $\begin{array}{l}\text { Incomplete design and details of } \\
\text { components. Inadequate } \\
\text { description of product. }\end{array}$ & $\begin{array}{l}\text { Partial schematics of design and } \\
\text { details of components. }\end{array}$ & $\begin{array}{l}\text { Comprehensive schematics of } \\
\text { design and details of all } \\
\text { components. Logical sequence } \\
\text { and description. }\end{array}$ & 10 & \\
\hline Conclusion & $\begin{array}{c}\text { There is little reflection on the } \\
\text { work done, or the strengths and } \\
\text { weaknesses. Implications of the } \\
\text { work are ignored. }\end{array}$ & $\begin{array}{l}\text { Some reflection on the work } \\
\text { done. Some implications of the } \\
\text { work are discussed. Continuation } \\
\text { work is identified. }\end{array}$ & $\begin{array}{l}\text { Strengths and weaknesses clearly } \\
\text { stated. Implications of the project } \\
\text { work are discussed. Suggestions } \\
\text { are made for continuation work. }\end{array}$ & 5 & \\
\hline \multicolumn{6}{|c|}{ Writing Performance } \\
\hline Criteria & $\begin{array}{l}\text { Does Not Meet } \\
\text { Expectations }\end{array}$ & Meets Expectations & Exceed Expectations & Weight & Score \\
\hline $\begin{array}{l}\text { Structure/ } \\
\text { Formatting }\end{array}$ & $\begin{array}{l}\text { Format is unprofessional and } \\
\text { incomplete. Paragraphs are } \\
\text { poorly organized; use of sections } \\
\text { is illogical and hinders document } \\
\text { navigation. }\end{array}$ & $\begin{array}{l}\text { Good quality formatting and } \\
\text { complete. Paragraphs are usually } \\
\text { well-organized; use of sections is } \\
\text { logical and generally allows easy } \\
\text { navigation of the document. }\end{array}$ & $\begin{array}{l}\text { Professional, consistent and } \\
\text { complete formatting. Well- } \\
\text { organized, use of sections is } \\
\text { logical and allows easy } \\
\text { navigation of the document. }\end{array}$ & 10 & \\
\hline Mechanics & $\begin{array}{c}\text { Sentences are poorly written with } \\
\text { numerous incorrect word choices } \\
\text { and errors in grammar, } \\
\text { punctuation and spelling. }\end{array}$ & $\begin{array}{l}\text { Sentences are generally well- } \\
\text { written with few incorrect word } \\
\text { choices or errors in grammar, } \\
\text { punctuation and spelling. }\end{array}$ & $\begin{array}{l}\text { Sentences are well-written using } \\
\text { professional language and the } \\
\text { text is free of errors in grammar, } \\
\text { punctuation and spelling. }\end{array}$ & 15 & \\
\hline $\begin{array}{l}\text { Documentation } \\
\text { / References }\end{array}$ & $\begin{array}{l}\text { Fails to correctly document any } \\
\text { sources or to utilize appropriate } \\
\text { citation forms. }\end{array}$ & $\begin{array}{c}\text { Most sources are correctly } \\
\text { documented and appropriate } \\
\text { citation forms are generally } \\
\text { utilized. }\end{array}$ & $\begin{array}{l}\text { All sources are correctly and } \\
\text { thoroughly documented and } \\
\text { appropriate citation forms are } \\
\text { utilized throughout. }\end{array}$ & 5 & \\
\hline
\end{tabular}

\section{Specific Comments}

